\title{
MICROSTRUCTURE OF CO-EVAPORATED COCr FILMS WITH PERPENDICULAR ANISOTROPY
}

\author{
H. van Kranenburg, J.C. Lodder, Y. Maeda*, L. Toth** and Th.J.A. Popma
}

University of Twente, P.O. Box 217, $7500 \mathrm{AE}$ Enschede, The Netherlands * NTT Basic Research Laboratories, Tokai, Ibaraki, 319-11, Japan ** on leave from Res. Inst. for Technical Physics, P.O. Box 76, H-1325 Budapest, Hungary

Abstract - Co-evaporation of $\mathrm{Co}$ and $\mathrm{Cr}$ is applied to achieve good magnetic characteristics of the media deposited at low temperature. The opposed oblique incidence vapour flux induces a columnar alignment parallel to the evaporation plane. Further a process-induced segregation is present which introduces separated Co-rich and $\mathrm{Cr}$-rich regions. A selective etching process is carried out to find proof of this. The large increase of $M_{s}$ with respect to those of a homogeneous bulk $\mathrm{CoCr}$ layer with the same average composition confirms this. The columns, texture axes and $K_{1}$ axes are inclined towards the Co source, which was the main vapour flux direction. With increasing process temperature the tilting decreases.

\section{INTRODUCTION}

In deposited $\mathrm{CoCr}$ films relatively high substrate temperatures are necessary to achieve suitable magnetic properties. Therefore we started experiments with co-evaporation $[1,2]$ in where two vapour beams arrive from opposite directions. Shadowing effects during deposition play a major role in the film growth. The process geometry induces separated regions of the two materials that are used; in our case $\mathrm{Co}$ and $\mathrm{Cr}$. This so-called process-induced segregation enables us to deposit $\mathrm{CoCr}$ layers which have already enhanced perpendicular characteristics at low substrate temperature.

\section{EXPERIMENTAL}

In our present study we are concerned with the relation between deposition parameters, morphology and magnetic parameters. The evaporation is carried out in a high vacuum system with 2 e-beam sources. The angle of incidence $\alpha_{i}$ (defined by the angle between vapour flux and film normal) was $28^{\circ}$ for both the $\mathrm{Co}$ and the $\mathrm{Cr}$ vapour. The substrate was located in the common evaporation plane (defined by the 2 vapour flux directions). Heating of the substrate is done by using an infrared heater. This process temperature $\left(T_{p}\right)$ is measured. For the present experiments it is controlled at either $50^{\circ} \mathrm{C}$ (\#p1, \#s1) or $300^{\circ} \mathrm{C}$ (others). The actual substrate temperature is lower. Two film thicknesses (h) were investigated: $\mathrm{h} \simeq 0.7 \mu \mathrm{m}$ and $\mathrm{h} \simeq 1.4 \mu \mathrm{m}$. The deposition rate was $8 \AA 2 / \mathrm{s}$. The $\mathrm{Cr}$ content is $17-19$ at $\%$ for the samples on $\mathrm{Si}$ and $20-21$ at\% for the ones on polyimide (PI). No substrate pre-treatment was carried out. The properties of the films studied are shown in table 1.

\begin{tabular}{|c|c|c|c|c|c|c|c|c|c|c|c|}
\hline no & $\begin{array}{l}\text { sub- } \\
\text { strate }\end{array}$ & $\begin{array}{l}\text { at } \% \\
\mathrm{Cr} \\
\mathrm{XRF}\end{array}$ & $\begin{array}{c}\mathrm{h} \\
\mathrm{nm}\end{array}$ & $\begin{array}{l}\mathrm{M}_{\mathrm{s}} \\
\mathrm{kA} / \mathrm{m}\end{array}$ & $\begin{array}{l}\mathbf{H}_{\mathrm{c}_{\perp}} \\
\mathrm{kA} / \mathrm{m}\end{array}$ & $\begin{array}{c}\psi \\
\operatorname{deg}\end{array}$ & $\begin{array}{c}\gamma \\
\operatorname{deg}\end{array}$ & $\begin{array}{c}\mathrm{K}_{1} \\
10^{4} \\
\mathrm{Jm}^{-3}\end{array}$ & $\mid \begin{array}{c}\mathrm{K}_{2} \\
10^{4} \\
\mathrm{Jm}^{-3}\end{array}$ & $\begin{array}{l}\mathrm{K}_{\mathrm{i}} \\
10^{4} \\
\mathrm{Jm}^{-3}\end{array}$ & deg \\
\hline $\begin{array}{l}\mathrm{p} 1 \\
\mathrm{~s} 1\end{array}$ & $\begin{array}{l}\mathrm{PI} \\
\mathrm{Si}\end{array}$ & $\begin{array}{l}21.0 \\
18.2\end{array}$ & $\begin{array}{l}670 \\
720\end{array}$ & $\begin{array}{l}610 \\
639\end{array}$ & $\begin{array}{l}48 \\
38\end{array}$ & $\begin{array}{r}11 \\
9\end{array}$ & $\begin{array}{l}15 \\
11\end{array}$ & $\begin{array}{l}19.4 \\
17.8\end{array}$ & \begin{tabular}{|l|}
1.3 \\
0.6
\end{tabular} & $\begin{array}{l}1.0 \\
2.6\end{array}$ & $\begin{array}{r}6 \\
10\end{array}$ \\
\hline $\begin{array}{l}\mathrm{p} 2 \\
\mathrm{~s} 2\end{array}$ & $\begin{array}{l}\mathrm{PI} \\
\mathrm{Si}\end{array}$ & $\begin{array}{l}20.0 \\
17.1\end{array}$ & $\begin{array}{l}770 \\
800\end{array}$ & $\begin{array}{l}693 \\
753\end{array}$ & $\begin{array}{l}30 \\
44\end{array}$ & $\begin{array}{r}15 \\
8\end{array}$ & $\begin{array}{l}5 \\
7\end{array}$ & $\begin{array}{l}19.7 \\
19.8\end{array}$ & $\begin{array}{l}1.5 \\
1.4\end{array}$ & $\begin{array}{l}1.8 \\
2.1\end{array}$ & $\begin{array}{l}2 \\
0\end{array}$ \\
\hline $\begin{array}{l}\text { p3 } \\
\text { s3 }\end{array}$ & $\begin{array}{l}\mathrm{PI} \\
\mathrm{Si}\end{array}$ & \begin{tabular}{|l|}
20.7 \\
18.8
\end{tabular} & $\begin{array}{l}1350 \\
1550\end{array}$ & $\begin{array}{l}621 \\
655\end{array}$ & $\begin{array}{l}43 \\
51\end{array}$ & $\begin{array}{l}17 \\
16\end{array}$ & $\begin{array}{l}18 \\
17\end{array}$ & $\begin{array}{l}15.5 \\
20.7\end{array}$ & $\begin{array}{l}1.1 \\
1.6\end{array}$ & $\begin{array}{l}0.6 \\
2.2\end{array}$ & $\begin{array}{l}7 \\
4\end{array}$ \\
\hline
\end{tabular}

A VSM is used to measure the hysteresis behavior Magnitude and direction of the anisotropy axes are measured with a torque magnetometer. The structure is observed by high resolution SEM and TEM (in Bright Field Image mode BFI and Dark Field Image mode DFI). A selective etching process developed by [3] was applied to find proof of the segregation. The etchant is $0.217 \mathrm{~mol} \mathrm{HCl}+0.0410 \mathrm{~mol}$ $\left.\mathrm{HNO}_{3}\right) / 1$. This acid preferentially dissolves the Co-rich parts as a result of passivation of the $\mathrm{Cr}$-rich parts. Etching times varied between $2-30$ hours. TEM observations are carried out on as-thinned and etched samples. Thinning of the samples is done by ion milling. The remaining top layer of the films is observed. Compositions are measured locally by EDS. Average compositions are measured by XRF. Texture information is determined by XRD and Selected Area Diffraction (SAD).

\section{RESULTS AND DISCUSSION}

The structural properties will be discussed separately for the samples deposited at $\mathrm{T}_{\mathrm{p}}=50^{\circ} \mathrm{C}$ and $\mathrm{T}_{\mathrm{p}}=300^{\circ} \mathrm{C}$. Structural properties of the samples deposited at $T_{\mathrm{p}}=50^{\circ} \mathrm{C}$

A columnar structure was revealed by SEM observations, see fig.1. The columns are inclined towards the Co source. The angle that the columnar axes make with the film normal (appr. $15^{\circ}-20^{\circ}$ ) is smaller than the incidence angle $\alpha_{i}$. Both the shadowing effect and the second vapour beam from the $\mathrm{Cr}$ source are responsible for this. The selective etching and stress that is present give rise to microcracks, see fig. 1 . The direction of the cracks is perpendicular to the evaporation plane. This can be explained by the chemical inhomogenieties that are introduced by the process geometry. The columnar diameter is rather small, some $15-35 \mathrm{~nm}$ (confirmed by SEM and TEM). For a sputtered $\mathrm{CoCr}$ film of this thickness $(0.7 \mu \mathrm{m})$ a columnar diameter larger than $100 \mathrm{~nm}$ is usually grown. In the case of co-evaporated $\mathrm{CoCr}$ films the columnar diameter hardly seems to increase with film thickness. It may be restricted by the growth of separated columns.

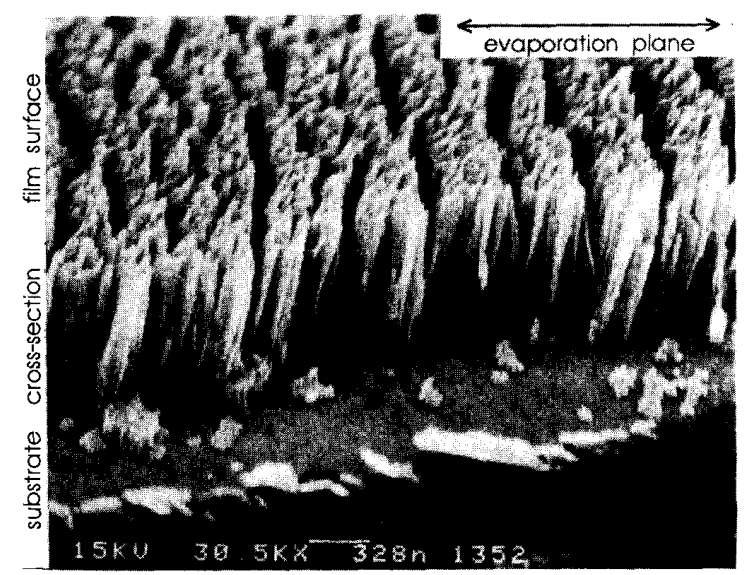

Fig. 1. SEM micrograph of a strongly etched sample (\#s1), showing the film surface and a cross section (tilt angle = $\left.30^{\circ}\right)$. The columns are inclined towards the Co-source.

A cross-sectional model for the morphology parallel to the evaporation plane is sketched in fig. 2 . Because most of the deposited material is $\mathrm{Co}$, the main oblique incidence direction is given by the Co vapour flux direction. Already deposited atoms will shadow adjacent regions from direct impingement, which leads to the inclined columnar growth towards the Co source. During film growth voids are likely to occur in between the columns. With limited adatom mobility, such as in this case $\left(T_{p}=50^{\circ} \mathrm{C}\right)$, the atoms will stick to a place very near to the initial impingement place. This can lead to process-induced segregation, where one side of the columns is Cr-rich. 


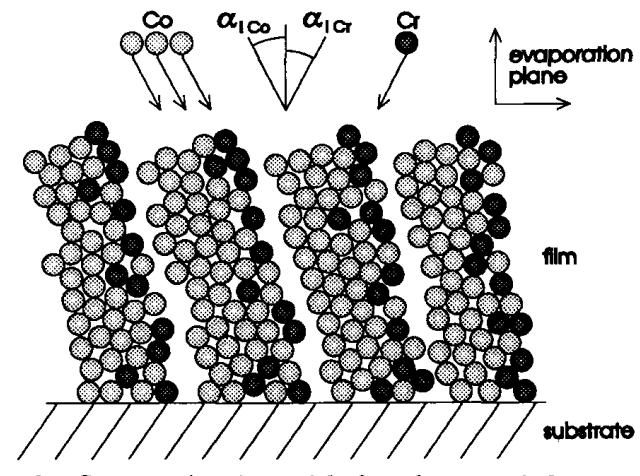

Fig. 2. Cross-sectional model for the morphology parallel to the evaporation plane.

Another structural feature that we observed with SEM (in planar view) is a columnar alignment parallel to the evaporation plane. With TEM observations this was even more clearly observed, see fig. 3. Both the direction of the columnar alignment and the dimensions are consistent with the SEM observations. Fig. 3. is a BFI of an as-thinned sample. The white stripes parallel to the evaporation plane (arrowed direction) are regions of lesser packing density. DFI supported that the crystal size is equal to the interwhite-stripe-distance. Crystallites are of elongated shape; the white stripes are their boundaries (along the long axis). Our direction of columnar alignment is different from the more often found bundles [4] (which are perpendicular to the evaporation plane) as reported in literature for one source oblique incidence deposition. However, the direction of alignment is known to depend on deposition parameters. A systematical study is in progress on our dual source geometry.

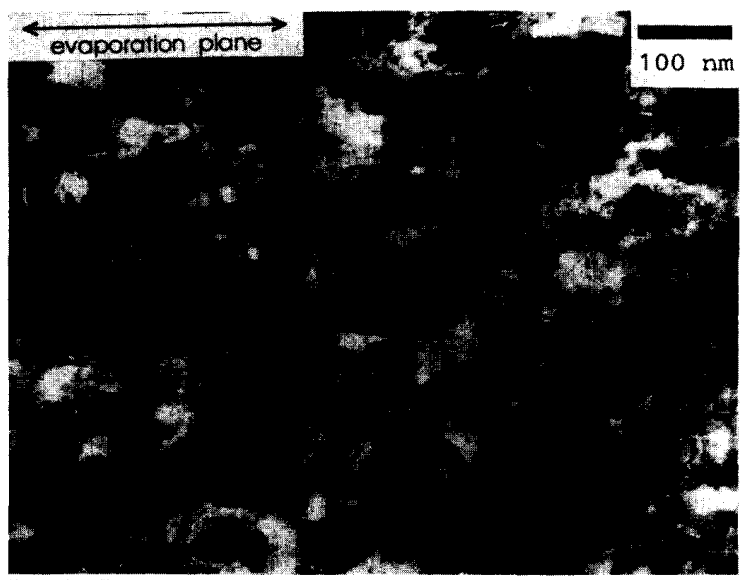

Fig. 3. TEM BFI of as-thinned sample \#p1. The direction of the evaporation plane is indicated by the arrow.

After selective etching the white stripes are more pronounced, thus revealing more clearly the columnar alignment (fig. 4a). Also CP-like stripes [3] (representing Co-rich areas) are introduced, see the enlargement in fig. 4b. These fine stripes, as they will be referred to hereafter, start to develop perpendicularly to the column boundaries (white stripes). The inter-stripe distance of those fine stripes $(<4 \mathrm{~nm})$ is smaller than those observed for sputtered $\mathrm{CoCr}$ [3]. In the sample shown in figs. 3 and 4 , the local Co content is $74.5 \% \mathrm{Co}$ in the as-thinned state and $62.9 \% \mathrm{Co}$ in the etched state. Such a decrease is typical for 12-30 hours of etching.

Both with XRD and SAD we only found the hexagonal close

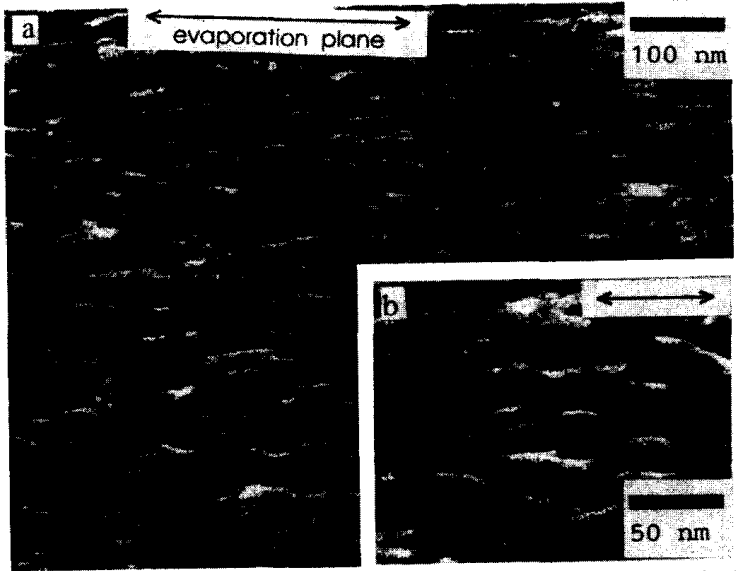

Fig. 4. TEM BFI of sample \#p1, which is chemically etched for 15 hours. Fig. $b$ is an enlargement of fig. $a$.

packed structure. Further the structure is polycrystalline. Diffraction rings appeared to have a non-uniform intensity, indicating the texture axis is inclined. This is checked by tilting the sample. Measuring rocking curves in both the evaporation plane and the transversal plane [1] enabled the inclination angle of the texture axis, $\delta$, to be estimated to be $6^{\circ}-8^{\circ}$ (see table 1), which is less than the column tilting. This indicates that the c-axis prefers to grow perpendicular to the substrate. Values of $\Delta \theta_{50}$ are $9^{\circ}$ for $\#$ p1 and $17^{\circ}$ for \#s1.

\section{Structural properties of the samples deposited at $T_{\mathrm{p}}=300^{\circ} \mathrm{C}$}

At higher process temperature the adatom mobility increases. Therefore a denser structure forms. With SEM we observed less pronounced columns than for the $50^{\circ} \mathrm{C}$ samples. Further their inclination angle is less $\left(<10^{\circ}\right)$. To give rise to the microcracks perpendicular to the evaporation plane longer etching times were needed. Both the denser structure and less stress (a lower crack density is observed) can be responsible for this.

The columnar alignment is less strong. Furthermore larger columns have grown $(15-60 \mathrm{~nm})$, their shape being no longer elongated for most of them. It is supported by DFI that the average crystal size is larger than the average interwhite-stripe-distance. Fig. 5 shows a BFI for a sample deposited at $\mathrm{T}_{\mathrm{p}}=300^{\circ} \mathrm{C}$ in the as-thinned state and the etched state is presented in fig. 6 . We got the impression from TEM observations done at higher magnifications, that at thin places of the specimen, CP structures with hexagonal symmetries are present.

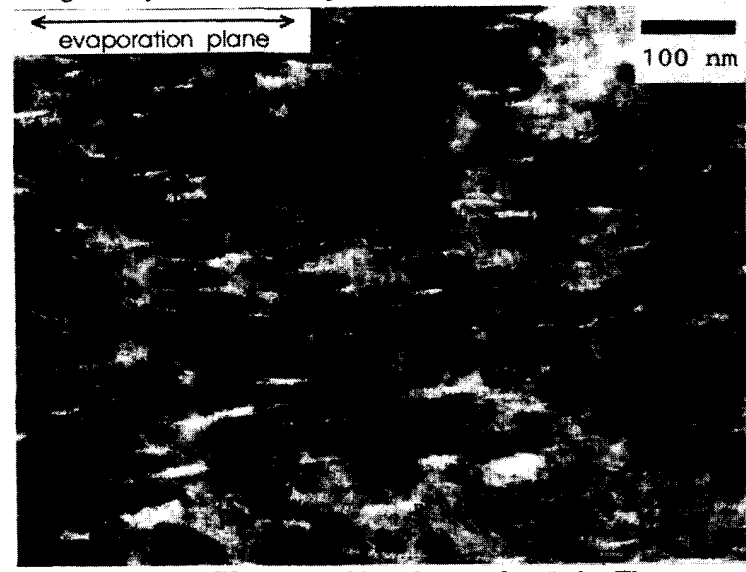

Fig. 5. TEM BFI of as-thinned sample \#p2. The arrow indicates the direction of the evaporation plane. 


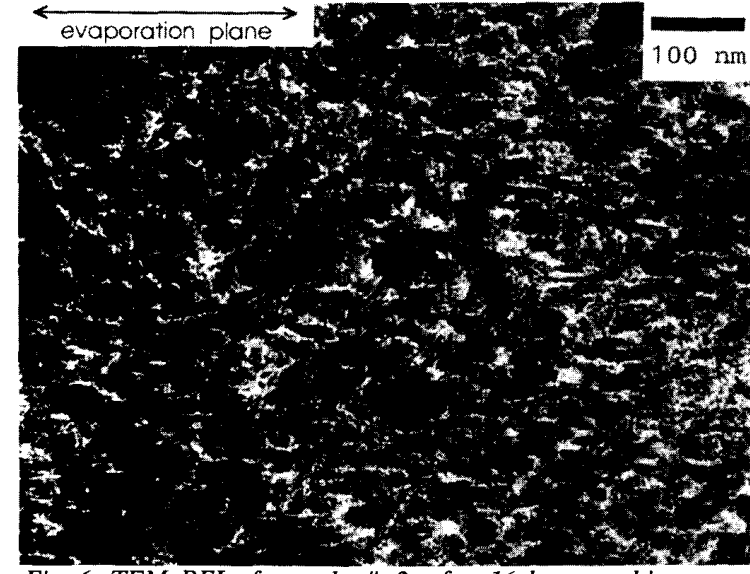

Fig. 6. TEM BFI of sample \#p2, after 16 hours etching.

In the sample shown in figs. 5 and 6 the local Co content decreased from 80.1 at $\%$ to 65.0 at $\%$ after etching for 16 hours. The structure is polycrystalline single phase hcp. Texture axes inclination is measured to be $0^{\circ}-2^{\circ}$. The dispersions around the c-axis are comparable to the $50^{\circ} \mathrm{C}$ samples: $\Delta \theta_{50}=8^{\circ}$ for $\# \mathrm{p} 2$ and $20^{\circ}$ for $\# \mathrm{~s} 2$.

Upon increasing the film thickness, the structure changes drastically. We observed a sample of $1.4 \mu \mathrm{m}$. In BFI the structure looks more granular and only few white stripes are observed. DFI showed that the crystallites are of elongated shape and the long side is formed by the white stripes. More TEM observations are needed to interpret and understand the structure of the thicker samples. The crystal diameter has increased to $20-80 \mathrm{~nm}$, and is still much smaller than in sputtered samples. The columnar inclination angle is appr. $15^{\circ}$. Texture axis inclination increased to $4^{\circ}-7^{\circ} . \Delta \theta_{50}$ increased to $20^{\circ}$.

Magnetic properties

Saturation magnetizations are much higher than the those for a homogeneous bulk $\mathrm{CoCr}$ layer (and also higher than for sputtered $\mathrm{CoCr}$ having the same average composition). The structural separation in $\mathrm{Co}$-rich and $\mathrm{Cr}$-rich regions causes this large deviation. The deviation also being large for the samples deposited at $\mathrm{T}_{\mathrm{p}}=50^{\circ} \mathrm{C}$, confirms the appearance of a process-induced segregation. The process temperature is far too low to produce such a large deviation solely by thermally enhanced segregation. The deviation being larger for the samples deposited at higher process temperature agrees well with this. Numerical data for $M_{s}$ is given in table 1 .

Coercivities are of moderate value and obey the previously measured relations of decreasing at higher $M$ and increasing with $T_{p}[1]$. The samples deposited at $T_{p}=300^{\circ} \mathrm{C}$ both have a higher $M_{s}$ and a higher $H_{c}$ (as a function of $M_{s}$ ) compared with the ones deposited at $\mathrm{T}_{\mathrm{p}}=50^{\circ} \mathrm{C}$.

The angle dependent VSM measurements are carried out in the two planes defined in fig. 7 . This yields 2 angledependent coercivities. The angle where the maximum $\mathrm{H}_{\mathrm{c}}$ is measured is shifted when measured in these planes. This implies that the anisotropy axis is inclined. The direction of this inclination is towards the Co source. Table 1 lists $\psi$ : the shift in angle where the maximum coercivity is measured. The torque curves are also measured in the two planes mentioned previously. A shift in angle where minimum torque applies is measured. Additionally, the torque curves are also measured in-plane. With these 3 measurements planes we were able to analyse the data [5] and find the different anisotropy axes and anisotropy constants. The inclination angles thus calculated for $\mathrm{K}_{1} \gamma$ agree well with $\psi$ as measured with the VSM (table 1). For the thinner samples deposited at $50^{\circ} \mathrm{C}$ and $300^{\circ} \mathrm{C}, \gamma$ is respectively $10^{\circ}-15^{\circ}$ and $5^{\circ}-10^{\circ}$. Higher adatom mobility during the film growth results in smaller tilting of the columns and texture axes and of the anisotropy axes. The thicker sample

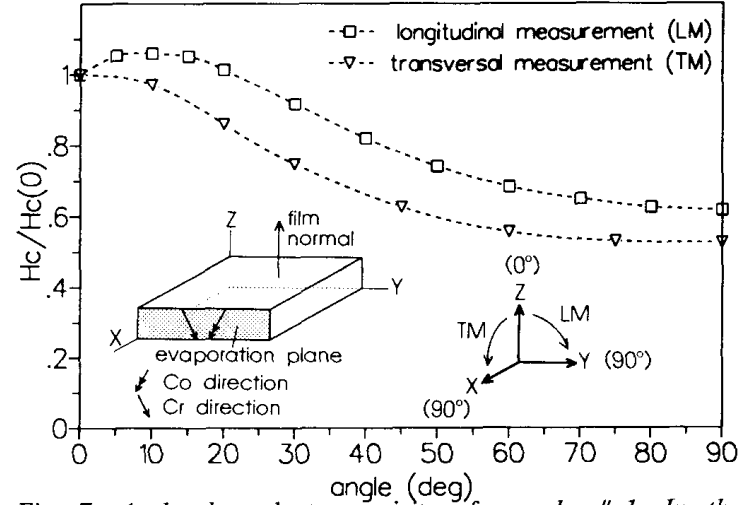

Fig. 7. Angle dependent coercivity of sample \#s1. In the longitudinal measurement the field is varied in the $Y Z$-plane, in the transversal one in the XZ-plane. Zero angle corresponds to an applied field $\perp$ to the substrate.

has a much larger inclination angle $\left(\gamma=16^{\circ}-18^{\circ}\right)$. This is related to the large $\Delta \theta_{50^{\circ}}$. For all samples $\gamma$ is larger than $\delta$. This indicates that besides crystal anisotropy also shape anisotropy of the columns is significant.

Typical $K_{1}$ values are $15-2010^{4} \mathrm{Jm}^{-3}$, typical $\mathrm{K}_{2}$ values are $1-210^{4} \mathrm{Jm}^{-3}$ (see table 1). All samples have a small in-plane anisotropy, its direction being parallel to the evaporation plane, which coincides with the direction of columnar alignment. The magnitude of the in-plane anisotropy is of the same order for all samples: $K_{-1} \simeq 1-210^{4} \mathrm{Jm}^{-3}$. py is of the same order for all samples: $K_{j} \simeq 1-210 \mathrm{Jm}$.
The hysteresis loss (measured by VSM) is a decreasing function of the angle between applied field and film normal. This, together with the shape of the hysteresis curves and the behavior of the angle dependent coercivity, implies that a rotational reversal of the magnetization dominates. It is due to the influence of an initial layer that a small amount of domain wall motion occurs. To minimize the initial layer and reduce the in-plane characteristics, we have already studied the application of seed layers [2]. In the near future we intend to apply a pre-treatment of the substrate.

\section{CONCLUSIONS}

The oblique incidence vapor flux causes a processinduced segregation as well as a columnar alignment parallel to the evaporation plane. Co-rich stripe-shaped areas are found at the column boundaries. With increasing process temperature non-elongated columns develop. The columnar axes are inclined towards the Co source at a smaller angle than the angle of incidence. The texture axes are also inclined, as are the anisotropy axes. The process-induced segregation results in an enhanced coercivity and saturation magnetization. A small in-plane anisotropy coincides with the direction of columnar alignment. At higher process temperature the column, texture and anisotropy axes tilting is less.

\section{ACKNOWLEDGEMENTS}

The authors are obliged to Mr. A.M. Otter for carrying out the SEM observations. The assistance of the EC CAMST initiative is also acknowledged.

\section{REFERENCES}

[1] F.A. Pronk, J.C. Lodder, IEEE Trans. Mag., vol. MAG-24, pp. 1744-1747, 1988.

[2] F.A. Pronk, J.C. Lodder, J. de Phys., vol. 12-49, pp.C8/1991-C8/1992, 1988.

[3] Y. Maeda, M. Takahashi, J. Magn. Soc. Jpn., vol. 13, no. S1, pp. 673-678, 1989 .

[4] K. Okamoto et al, J. Magn. Magn. Mat., vol 81, pp. 374-380, 1989.

[5] S. Swaving et al, J. Magn. Magn. Mat., vol. 67, pp. 155-164, 1987. 